REVISTA DE DERECHO UNED, NÚM. 13, 2013

\title{
¿QUÉ FUE DE LAS «PAGAS EXTRAORDINARIAS» DE LOS FUNCIONARIOS PÚBLICOS CON LA CRISIS?
}

\section{WHAT HAPPENED TO THE «EXTRA PAYMENTS» OF CIVIL SERVANTS DURING THE CRISIS?}

\section{MIGUEL RAMÓN PICÓ ENSEÑAT}

Doctor en Derecho Administrativo por la UNED ${ }^{1}$

Especialista Universitario en Derecho Urbanístico y Ordenación del Territorio, Experto Universitario en Derecho Civil Balear y Licenciado en Derecho por la Universitat de les Illes Balears

Funcionario del Consejo Insular de Mallorca, del cuerpo de Técnicos

Superiores de Gestión de Recursos Humanos.

Resumen: Este estudio pretende analizar qué es lo que jurídicamente han supuesto las medidas de austeridad respecto a las «Pagas Extraordinarias» como concepto retributivo inserto en el Sistema Retributivo Funcionarial.

Abstract: This study analyzes the legal effects of austerity measures over the "Extraordinary Payments» as a form of remuneration inserted in the Civil Servant's Remuneration System.

Palabras clave: Crisis financiera de 2008. Funcionarios. Pagas Extraordinarias. Sistema Retributivo Funcionarial.

Key words: 2008 Financial crisis. Civil servants. Extra Payments. Civil Servant's Remuneration System.

1 La tesis doctoral: "El Sistema de Fuentes de la Función Pública Local: Consecuencias de la coexistencia de Títulos Competenciales diferenciales» obtuvo la calificación de «Sobresaliente cum laude por unanimidad» de la Universidad Nacional de Educación a Distancia-Departamento de Derecho Administrativo. 
Recepción original: 14/11/2013

Aceptación original: 29/11/2013

Sumario: I. Prólogo: La crisis del 2008. II. Antecedentes: Configuración de las «Pagas Extraordinarias». III. Año 2010. IV. Año 2011. V. Año 2012. VI. Año 2013

\section{PROLOGO: LA CRISIS DEL 2008}

El lunes 15 de septiembre de 2008, con la quiebra de Lethman Brothers, se inició una crisis financiera de la cual todavía a día de hoy los mortales de a pie seguimos sufriendo sus terribles efectos. Muy probablemente resulte imprescindible ser economista para teorizar, o predecir, si -de acuerdo con los planteamientos de Nikolái Kondrátiev- «simplemente» nos encontramos ante un ciclo económico; pero con toda seguridad no hace falta ser economista para constatar -en muchísimos casos, en propia carne- la extrema virulencia, duración y magnitud de esta crisis. Circunstancias estas, unidas al hecho de que la causa también fuese una «burbuja» -no del ladrillo, sino de las acciones-, inducen a plantear no pocos paralelismos con el «Crack» del «Jueves Negro» del 24 de octubre de 1929; lo cual no es nada halagüeño y más si acude a nuestra memoria que el «Crack» desembocó en «La Gran Depresión» y que ésta culminó con la Segunda Guerra Mundial.

En España, frente a la crisis económica, primero el gobierno del PSOE, presidido por José Luis Rodríguez Zapatero y posteriormente el gobierno del PP, presidido por Mariano Rajoy Brey, adoptaron -y siguen adoptando- toda una serie de medidas, buena parte de las cuales han golpeado de lleno al funcionariado. Unas de las más importantes -que no las únicas- han sido las reducciones y la «supresión» / «suspensión» / «aplazamiento»² de las «Pagas Extraordinarias» de los Funcionarios Públicos.

El análisis de la incidencia de la crisis en la Función Pública ha tenido por parte de la Doctrina Jurídica distintos foros ${ }^{3}$, constituyen-

2 Sobre esta incerteza terminológica relativa a la «Paga Extraordinaria» de Diciembre de 2012, nos remitimos a lo que posteriormente se dirá en el apartado «V. AÑO 2012».

3 Sobre este particular es de justicia destacar la gran implicación del Departamento de Derecho Administrativo de la UNED en la gestación de las Jornadas sobre "Crisis económica y Función Pública», realizadas el 29 de febrero y 1 de marzo de 2012 en la Facultad de Derecho de la UNED en Madrid y en el Curso «Crisis econó- 
do el monográfico codirigido por FUENTETAJA y CANTERO ${ }^{4}$, texto de obligada lectura.

En el momento actual, podemos afirmar que en esta tempestuosa travesía a la cual nos hemos visto arrastrados, la popa de nuestra nave ya nos ofrece una amplia perspectiva del pasado, más que suficiente para posibilitar su análisis. La perspectiva que del futuro desde la proa pueda otearse todavía se nos vislumbra muy incierta; opinión personal esta que deseo que el tiempo, como juez inexorable, ponga de manifiesto como un error más de la condición humana de éste que la escribe y como un acierto de aquellos que ya han visto «brotes verdes» 0 «luz al final del túnel».

En este contexto actual consideramos que toma plena carta de naturaleza llevar a término un análisis jurídico que aborde lo que las medidas de austeridad respecto a las «Pagas Extraordinarias» de los Funcionarios Públicos supusieron, han supuesto, siguen suponiendo y -desgraciadamente si alguien no lo remedia- muy probablemente sigan suponiendo. El objeto de este análisis jurídico creemos que debe buscar dar respuesta a dos grandes cuestionamientos: ¿qué sucedió? y ¿si jurídicamente, en nuestro Estado de Derecho, era admisible lo que sucedió?

Intentar dar respuesta a ¿qué sucedió? constituye el objeto de este artículo. Para ello nuestra línea expositiva seguirá el devenir de las «Pagas Extraordinarias» de los Funcionarios Públicos como concepto retributivo a través de una génesis que arranca del Sistema Retributivo establecido en la ancestral Ley de Funcionarios Civiles del Estado de 1954 y que llega hasta nuestros días. Dada la naturaleza de su finalidad en su contenido resulta obligado tomar el Derecho Positivo como fuente cognoscitiva fundamental.

Dar respuesta al cuestionamiento de ¿si jurídicamente, en nuestro Estado de Derecho, era admisible lo que sucedió? sin ningún tipo de dudas es la segunda pregunta que inmediatamente emerge una vez analizado en profundidad lo acontecido. Es verdad que buscar la respuesta a este dubio no constituye el objeto de este artículo. Pero no es menos verdad que como juristas del Derecho Funcionarial no podemos -ni debemos- resistirnos a la tentación de poner de manifiesto, aunque sea a título de mera indicación, la

mica y Función Pública», realizado del 4 al 6 de julio de 2011 en la sede de la UNED en Palma de Mallorca y retransmitido por internet.

4 FUENTETAJA PASTOR, J.A. y CANTERO MARTÍNEZ, J. (Directores) et alii, Crisis Económica y Función Pública, Editorial Aranzadi SA, Navarra, 2012, Primera edición. 
importancia de las cuestiones que en su análisis van a suscitarse y que prima facie pensamos que conducirían a analizar lo sucedido respecto a las «Pagas Extraordinarias» desde la perspectiva de límites de la Potestas variandi del legislador respecto al «estatus» funcionarial y más concretamente en analizar si las medidas adoptadas, habida cuenta su extrema dureza y la inexistencia de precedentes, han lesionado o comprometido Derechos y Libertades constitucionales.

Desde el punto de vista de la jurisprudencia como fuente cognoscitiva podemos anticipar sin ningún tipo de dudas que en el debate de tan importantes cuestiones existiría una referencia, entre otras, a la primeriza Sent. 186/2013, de 29 de mayo de 2013, del Juzgado Contencioso-Administrativo núm. 1 de los de Palencia; a las sentencias del Tribunal Constitucional 99/1987, de 11 de junio (RTC/1987/99), 57/1982, de 27 de julio (RTC/1982/57) y 108/1996 de 29 de julio (RTC/1986/108); a la consolidada jurisprudencia del Tribunal Supremo configurada por las sentencias 30.10.1979 (RJ/1979/3614), 8.5.1981 (RJ/1981/1880), 29.11.1986 (RJ/1986/6643), 23.10 .1987 (RJ/1988/10202), 11.3.1988 (RJ/1988/2260), 29.6.1991 (RJ/1991/5084), 3.10.1992 (RJ/1992/7782), 5.10.1992 (RJ/1992/7789), 18.1.1993 (RJ/1993/321), 13.7.1993 (RJ/1993/5636). 18.10.1993 (RJ/1993/8622), 16.5.1995 (RJ/1995/4119), 12.2.1996 (RJ/1996/1566), 22.2.1996 (RJ/1996/1625), 17.3.1997 (RJ/1997/2343), 2.6.1997 (RJ/1997/4918), 20.4.1998 (RJ/1998/4524) y 28.9.2001 (RJ/2001/9020); al reciente pronunciamiento del Tribunal Constitucional Portugués en su Acuerdo núm. 187/2013, como fuente de Derecho Comparado; y, como no, a la futura resolución que adopte nuestro Tribunal Constitucional sobre la supresión/suspensión de la Paga Extraordinaria de 2012.

\section{ANTECEDENTES: CONFIGURACIÓN DE LAS «PAGAS EXTRAORDINARIAS»}

Para una correcta comprensión jurídica de la magnitud de lo acontecido respecto a las «Pagas Extraordinarias» de los Funcionarios Públicos procede remontarnos a los antecedentes históricos en su configuración, antes dentro del Sistema Retributivo de la LMRFP y posteriormente dentro del EBEP.

En esa línea expositiva, como cuestión previa primaria deviene obligado matizar que en el Sistema Retributivo Funcionarial de la 
LMRFP y del EBEP ni el «Sueldo ${ }^{5}$ » es «sueldo ${ }^{6}$, ni las «Pagas Extraordinarias» son "pagas extraordinarias». Dicho de otra manera, a pesar de su nomen iuris, las «Pagas Extraordinarias» no son "pagas», sino «Conceptos Retributivos» dentro de las «pagas» de junio y diciembre ${ }^{7}$.

Como segunda cuestión previa procede también matizar que hasta fechas muy recientes las conocidas por los Trabajadores como «pagas dobles», para los Funcionarios tampoco eran «pagas dobles».

Respecto a esta última afirmación procede observar que inicialmente en el «Sistema Retributivo» surgido con la LMRFP en su art. veintitres.2.c) literalmente se decía que las «Pagas Extraordinarias» estarían integradas [...] por un importe mínimo cada una de ellas de una mensualidad de sueldo y trienios, [...]. La conjunción de dicho literal y del sistema de distribución competencial en Materia de «régimen estatutario de los funcionarios» establecida en el 149.1. ${ }^{\circ} 18 .^{a}$ de la CE'78 como Título Competencial, o la posible incidencia de otras

5 Strictu sensu en el «Sistema Retributivo» surgido con la LMRFP, el literal del derogado artículo 23.2.a), expresamente ya decía que el «Sueldo» era un «Concepto Retributivo» de las «Retribuciones Básicas». En esa misma línea en el «Sistema Retributivo» surgido con el EBEP, su regulación, y más concretamente el artículo 23.a), sigue manteniéndose que el «Sueldo» es un «Concepto Retributivo» de las «Retribuciones Básicas».

6 Lato sensu en el DRAEL la primera acepción del término «sueldo» es la de «Remuneración regular asignada por el desempeño de un cargo o servicio profesional», de lo cual se infiere su interpretación común como la liquidación de todos los conceptos retributivos y retenciones, es decir, aquello que se percibe.

7 Una de las evidencias de que las «Pagas Extraordinarias» no eran, ni son, «pagas extraordinarias» es el hecho que el legislador de la LMRFP y del EBEP las reconoce como «Conceptos Retributivos» con una determinada naturaleza:

En el «Sistema Retributivo» surgido con la LMRFP, la literalidad del derogado artículo 23.2.c) expresamente ya establecía que las «Pagas Extraordinarias», al igual que el «Sueldo» y los «Trienios» eran «Retribuciones Básicas». Naturaleza esa que no se modificaba ni por el hecho de que el «Sistema de Liquidación o cuantificación» fuese diferencial por la extensión del «Período Retributivo»; ni por el hecho de que a partir del 2003 uno de los factores de cuantificación fuese el «Complemento de Destino», el cual, de acuerdo con el derogado LMRFP 23.3.a), indudablemente ostentaba la naturaleza de «Retribución Complementaria».

En el «Sistema Retributivo» surgido con el EBEP, el artículo 22.4 se ha centrado en poner de manifiesto, bien es verdad que implícitamente, la naturaleza mixta de las «Pagas Extraordinarias» en tanto en cuanto, por una parte, sigue cuantificándose en función de los componentes de «Sueldo» y «Trienios»-ex EBEP 22.2.in fine-, que tienen la naturaleza de «Retribuciones Básicas», y, por otra parte, también se cuantifica incorporando "Componentes» de las "Retribuciones Complementarias» («Componentes» que no han de retribuir los «Factores» descritos en EBEP 24.c) y d)). 
normas con diferente Título Competencial ${ }^{8}$, conducía a pensar en la posibilidad de superar tales mínimos «para colectivos específicos» -como dice CORRAL ${ }^{9}$-, o por la vía de un desarrollo legislativo autonómico. Dicho autor ${ }^{10}$ sin embargo negaba tal posibilidad a partir de la modificación operada en el artículo veinticuatro.1 de la LMRFP por el artículo $50^{11}$ de la LALPGE'2003. Posicionamiento éste que no compartimos totalmente habida cuenta que el literal del artículo veintitres.2.c) de la LMRFP, no fue alterado por la LALPGE'2003, por lo que seguía plenamente vigente. Lo cual no niega o bien la posible existencia de una antinomia entre los artículos veintitres.2.c) y veinticuatro.1, ambos de la LMRFP; o bien la necesidad de reinterpretar sistemática y literalmente ambas normas; opción esta última que muy probablemente conduciría a reducir las competencias para una eventual superación de los referidos mínimos exclusivamente al legislador estatal como Fuente Material y a la Legislación Básica en Materia de Régimen Estatutario de los Funcionarios Públicos con Título Competencial en el artículo 149.1. ${ }^{\circ} 18 .^{a}$ de la CE'78 como Fuente Formal más probable. Sin perjuicio de la referida discusión teorética, lo cierto históricamente es que desde la implantación del «Sistema Retributivo» de la LMRFP durante muchísimos años aquel mínimo devino también máximo.

La incorporación del "Complemento de Destino» y del «Complemento Específico» como componentes de las «Pagas Extraordinarias» ${ }^{12}$, ha sido, como se indica en la obra coordinada

8 Verbi gratia legislación en Materia de «Régimen Jurídico de la Administración Local» con Título Competencial en CE'78.149.1. ${ }^{\circ} 18 .{ }^{\mathrm{a}}$

9 CORRAL VILLALBA, Juan, Régimen Económico del Personal de las Administraciones Públicas, Editorial Aranzadi SA, Navarra, 2006, primera edición, p. 41.

10 Op.cit. p. 41.

11 Originariamente el LMRFP.veinticuatro.1 decía:

[...] Las cuantías de las retribuciones básicas serán iguales en todas las Administraciones Públicas para cada uno de los grupos en que se clasifican los Cuerpos, Escalas, Categorías o Clases de funcionarios. El sueldo de los funcionarios del grupo A no podrá exceder en más de tres veces el sueldo de los funcionarios del grupo E.[...]

Con la modificación establecida por LALPGE'2003.50 el LMRFP.veinticuatro.1 paso a decir:

[...] Las cuantías de las retribuciones básicas de los párrafos a) y b) del apartado 2 del artículo 23 de esta Ley, serán iguales en todas las Administraciones públicas, para cada uno de los grupos en que se clasifican los cuerpos, escalas, categorías o clases de funcionarios. Asimismo las cuantías de las pagas extraordinarias serán iguales, en todas las Administraciones públicas, para cada uno de los grupos de clasificación según el nivel del complemento de destino que se perciba. [...]

12 Nos remitimos a lo que posteriormente se indica en relación a si el «Complemento Específico» acaba siendo componente de la «Paga Extraordinaria» o de la «Paga Adicional de Complemento Específico». 
por SEQUEIRA ${ }^{13}$, algo progresivo; dentro de un proceso que, como veremos a continuación, arranca en el 2003.

Respecto al "Complemento de Destino», en el Capítulo XIX.d) ${ }^{14}$ de los AAS'2003-4 se acordó una incorporación porcentual progresiva de la cuantía del "Complemento de Destino» en las «Pagas Extraordinarias». Lo cual se materializó en la LPGE'2003 ${ }^{15}$ con la incorporación del 20\% del CD, en la LPGE'2004 ${ }^{16}$ con la incorporación del $40 \%$ del CD, en la LPGE'2005 ${ }^{17}$ con la incorporación del $60 \%$ del CD, en la LPGE'2006 ${ }^{18}$ con la incorporación del 80\% del CD en la «Paga Extraordinaria» de junio y del 100\% del CD en la «Paga Extraordinaria» de diciembre y, finalmente, en la LPGE'2007 ${ }^{19}$ con la incorporación del 100\% del CD a las dos «Pagas Extraordinarias».

Respecto al "Complemento Específico», en el artículo 2. ${ }^{20}$ de los AAS’2006 se acordó la intención de acordar (y valga la redundancia) dentro de los 2 años siguientes la integración de la cuantía del «Complemento Específico» en las «Pagas Extraordinarias». Lo cual se materializó en la LPGE'200721 estableciendo un incremento

13 SEQUEIRA DE FUENTES, Marcial, et alii, Memento Práctico -Empleado Público- 2010-2011, Ediciones Francis Lefebvre, SA, Madrid, 2010, p. 204 y 205, marginal 1716.

${ }_{14}$ AAS'2003-4.TÍTULO VI. CAPÍTULO XIX. Medidas de ordenación retributiva, modernización y mejora de la calidad

Para el cumplimiento de los objetivos de modernización y mejora de la Administración contenidos en este Acuerdo, se articulan las siguientes medidas

[...] d) Modificación de las pagas extraordinarias:

Las pagas extraordinarias de los funcionarios en servicio activo a los que resulte de aplicación el régimen retributivo de la Ley 30/1984, de 2 de agosto, de Medidas para la Reforma de la Función Pública, tendrán un importe, cada una de ellas, equivalente a una mensualidad de sueldo y trienios, más un 20 por 100 del complemento de destino mensual, en el año 2003, y del 40 por 100 del mismo, en el año 2004. [...]

15 Vid. LPGE'2003.25.Uno.B).

16 Vid. LPGE'2004.19.Dos.2p. en concordancia con LPGE'2004.25.Uno.B).in fine.

17 Vid. LPGE'2005.19.Dos.2p. en concordancia con LPGE'2005.25.Uno.B).in fine.

18 Vid. LPGE'2006.19.Dos.2p. en concordancia con LPGE'2006.25.Uno.B).in fine.

19 Vid. LPGE'2007.21.Tres.1p. en concordancia con LPGE'2007.27.Uno.B).in fine.

20 AAS'2006.2- MODIFICACIONES DE LAS PAGAS EXTRAORDINARIAS.

[...] B - COMPLEMENTO ESPECÍFICO

Las partes firmantes manifiestan su intención de alcanzar un Acuerdo para los próximos dos años al de aplicación de este Acuerdo, en el que las pagas extraordinarias incluyan, además, el 100\% del total del complemento específico mensual.

21 LPGE'2007:

[...] EM.IV

Adicionalmente a los citados incrementos, se prevé un incremento del 1 por 100 de la masa salarial que se destinará al aumento del complemento especifico, o concepto adecuado, con el objeto de lograr progresivamente, en sucesivos ejercicios, una acomodación de tales complementos, que permita su percepción en 14 pagas al año.

[...] 21.Cuatro.1p: 
adicional de la masa salarial de los funcionarios del 1\% con la finalidad de aumentar progresivamente el «Complemento Específico» en diversos ejercicios hasta lograr [...] su percepción en 14 pagas al año, doce ordinarias y dos adicionales en los meses de junio y diciembre. [...]. En idénticos términos se estableció en la LPGE'2008 ${ }^{22}$ y en LPGE'2009²3. En la LPGE'2010 ya no existía mención alguna a ese incremento adicional de masa salarial, bien es verdad que en el artículo 28.Uno.D).2p. de dicha LPGE'2010 ya se decía: «El complemento específico anual se percibirá en catorce pagas iguales de las que doce serán de percibo mensual y dos adicionales, del mismo importe que una mensual, en los meses de junio y diciembre, respectivamente.»

Adicionalmente a lo previsto en el apartado Dos de este mismo artículo, la masa salarial de los funcionarios en servicio activo a los que resulte de aplicación el régimen retributivo de la Ley 30/1984, de 2 de agosto, de Medidas para la Reforma de la Función Pública, así como la del resto del personal sometido a régimen administrativo y estatutario, experimentará un incremento del 1 por 100 que se destinará al aumento del complemento específico, o concepto adecuado, con el objeto de lograr, progresivamente en sucesivos ejercicios, una acomodación de tales complementos que permita su percepción en 14 pagas al año, doce ordinarias y dos adicionales en los meses de junio y diciembre. [...]

[...] 23. Uno

Con efectos de 1 de enero del año 2007, las cuantías de los componentes de las retribuciones del personal del sector público estatal sometido a régimen administrativo y estatutario serán las derivadas de la aplicación de las siguientes normas:

a) Las retribuciones básicas de dicho personal, así como las complementarias de carácter fijo y periódico asignadas a los puestos de trabajo que desempeñen, experimentarán un crecimiento del 2 por 100 respecto de las establecidas para el ejercicio de 2006, sin perjuicio de lo establecido en los apartados Tres y Cuatro del artículo 21 de la presente Ley y, en su caso, de la adecuación de las retribuciones complementarias cuando sea necesaria para asegurar que las asignadas a cada puesto de trabajo guarden la relación procedente con el contenido de especial dificultad técnica, dedicación, responsabilidad, peligrosidad o penosidad del mismo. [...]

[...] 27.Uno.D)

El complemento específico que, en su caso, esté asignado al puesto que se desempeñe, cuya cuantía, sin perjuicio de lo previsto en el artículo 23.Uno.a), experimentará con carácter general un incremento del 2 por 100 respecto de la aprobada para el ejercicio de 2006.

Adicionalmente, en aplicación de lo dispuesto en el artículo 21.Cuatro, primer párrafo, de la presente Ley, los complementos específicos anuales resultantes de la operación anterior, experimentarán los incrementos lineales que se recogen en la siguiente tabla: [...]

El complemento específico anual que resulte de ambos incrementos, se percibirá en catorce pagas, de las que 12 serán iguales y de percibo mensual y las dos restantes, que se percibirán en los meses de junio y diciembre, serán de un tercio de la percibida mensualmente. [...]

22 Vid. LPGE'2008.EM.IV.3p,, artículo 22.Tres.in fine y artículo 24.Uno.a).1p.

23 Vid. LPGE'2009.EM.IV.3p., artículo 22.Tres.1p. y artículo 24.Uno.a).1p. 
La fórmula jurídica de incorporación del «Complemento Específico» a las «Pagas Extraordinarias» fue diferente y, a nuestro juicio, mucho más deficiente técnicamente que la articulada para la incorporación del «Complemento de Destino», lo cual se pone de manifiesto en los no pocos problemas que planteó:

1) El primer problema tiene su causa en que si bien es verdad que el artículo 22.4 del EBEP definitivamente ha consolidado dicha incorporación; no es menos verdad que al tener dicho artículo su sede en el Título III, Capítulo III, tal y como dice SEQUEIRA ${ }^{24}$, su eficacia ex DF.Cuarta.2.1p. del EBEP queda diferida a la entrada en vigor de las Leyes de Función Pública que desarrollen el EBEP. A pesar de ello no hemos de olvidar que, como se ha expuesto, por la vía de las diferentes leyes de presupuestos generales del Estado, se haya estado regulando una consolidación plena del «Complemento Específico» dentro de las «Pagas Extraordinarias».

2) El segundo problema tiene su causa en la diferencia significativa entre los literales de la regulación para la integración del «Complemento de Destino» y del «Complemento Específico». De tal manera que, tomando como ejemplo la LPGE'2013, resulta evidente y manifiesto que la regulación que se establece respecto al «Complemento de Destino» en el artículo 26.Uno.B).1 $\mathrm{p}^{25}$ de la LPGE'2013 y la regulación que se establece respecto al «Complemento Específico» en el artículo 26.Uno.D).2p ${ }^{26}$, también de la LPGE'2013, no solo no son iguales, sino que además resulta que el artículo 26.Uno.B).1p. se refiere a las cuantías que la integran como «componentes» de las "Pagas Extraordinarias», mientras que el artículo 26.Uno.D).2p. no se refiere a las «Pagas Extraordinarias». Haciendo de ambos artículos una interpretación en el sentido propio de sus palabras y una interpretación contextual, ambas ex 3.1 del CC, resulta obligado concluir que, a diferencia del «Sueldo», los «Trienios» y el "Complemento de Destino», cuyas cuantías se configuraban como «componentes» de las «Pagas Extraordinarias»,

24 Op.cit. p. 205, marginal 1716

25 LPGE'2013.26.Uno.B).1p:

Las pagas extraordinarias, que serán dos al año, una en el mes de junio y otra en el mes de diciembre, y que se devengarán de acuerdo con lo previsto en el artículo 33 de la Ley 33/1987, de 23 de diciembre, de Presupuestos Generales del Estado para 1988. Cada una de dichas pagas incluirá las cuantías de sueldo y trienios fijadas en el artículo 22.Cinco.2 de esta Ley y del complemento de destino mensual que se perciba.

26 LPGE'2013.26.Uno.D).2p:

El complemento específico anual se percibirá en catorce pagas iguales de las que doce serán de percibo mensual y dos adicionales, del mismo importe que una mensual, en los meses de junio y diciembre, respectivamente 
el «Complemento Específico» se configuraba como «componente» de las «Pagas Adicionales de Complemento Específico» ergo no de la «Paga Extraordinaria». Por el contrario, una interpretación de acuerdo con los antecedentes histórico-legislativos, también ex 3.1 del CC, situándonos en la génesis primigenia de los AAS'2003-427 en relación al "Complemento de Destino», y de los AAS'2006 ${ }^{28}$ en relación al "Complemento Específico», concluye una coincidencia originaria en postular la integración de las cuantías de ambos conceptos retributivos en las «Pagas Extraordinarias». Es más, también con un posicionamiento contrario, una interpretación sistemática, también ex 3.1 del CC, a la luz del artículo 22.4.in fine del EBEP difícilmente podría admitir que la cuantía del «Complemento Específico» relativa a la «Pagas Adicionales» no se sumase en la cuantificación de las «Pagas Extraordinarias». En todo caso, esta dialéctica en la estructuración del Sistema Retributivo Funcionarial, causada única y exclusivamente por la deficiente técnica legislativa empleada, la única trascendencia en la praxis que ha tenido hasta la fecha ha sido la discutible posible aparición de un nuevo concepto retributivo denominado «Paga Adicional del Complemento Específico» en las nóminas de los funcionarios cuya cuantía se determina por el «Complemento Específico».

3) Un tercer problema se dio en aquellas comunidades autónomas o corporaciones locales en donde, habida cuenta la cuantía de la masa salarial de los «Complementos Específicos», la reserva adicional del $1 \%$ de la masa salarial devenía insuficiente para la consecución del objetivo de unas «Pagas Adicionales» del 100\% del «Complemento Específico». Las «originales» soluciones articuladas en algunos casos no dejan de suscitar no pocos cuestionamientos jurídicos.

27 AAS'2003-4.TÍTULO VI. CAPÍTULO XIX. Medidas de ordenación retributiva, modernización y mejora de la calidad

Para el cumplimiento de los objetivos de modernización y mejora de la Administración contenidos en este Acuerdo, se articulan las siguientes medidas

[...] d) Modificación de las pagas extraordinarias:

Las pagas extraordinarias de los funcionarios en servicio activo a los que resulte de aplicación el régimen retributivo de la Ley 30/1984, de 2 de agosto, de Medidas para la Reforma de la Función Pública, tendrán un importe, cada una de ellas, equivalente a una mensualidad de sueldo y trienios, más un 20 por 100 del complemento de destino mensual, en el año 2003, y del 40 por 100 del mismo, en el año 2004. [...]

28 AAS'2006.2- MODIFICACIONES DE LAS PAGAS EXTRAORDINARIAS.

[...] B - COMPLEMENTO ESPECÍFICO

Las partes firmantes manifiestan su intención de alcanzar un Acuerdo para los próximos dos años al de aplicación de este Acuerdo, en el que las pagas extraordinarias incluyan, además, el 100\% del total del complemento específico mensual. 


\section{AÑO 2010}

Lo expuesto hasta ahora constituía la génesis, dentro del «Sistema Retributivo Funcionarial» de la LMRFP y del EBEP, del «Régimen Jurídico» de las "Pagas Extraordinarias» que arriba al año 2010. Año este, que los funcionarios, y aquellos que de ellos dependían, lo recordarán siempre no precisamente por ser aquel en que España ganó el «Mundial».

El 1 de enero de 2010 iniciaba su andadura el Año Jacobeo con la asunción por parte de España de la Presidencia del Consejo de la Unión Europea. Desde el punto de vista de las retribuciones de los Funcionarios Públicos, ese ejercicio presupuestario se configuraba inicialmente con la regulación establecida en la LPGE'2010, aplicada en la correspondiente Instrucción de Nóminas ${ }^{29}$.

El 12 de mayo de 2010 anno domini cristiano -26 de Iyar del año 5770 de la creación del mundo según el calendario judío; 28 de Jumada I del año 1431 de la Hégira, según el calendario musulmánel entonces Presidente del Gobierno José Luis Rodríguez Zapatero -después de haber negado más de tres veces la existencia de una crisis y tras una reunión con la Canciller Alemana Sra. Merkel (de la cual no son pocas las leyendas que en el "ciberespacio» han circulado sobre lo que allí aconteció)- pasa a la historia de la Función Pública anunciando -entre otras medidas- la reducción de las retribuciones de los funcionarios un 5\% «de media». La imprecisión de lo que suponía tal matización se despejó a los pocos días con el Real Decreto-ley 8/2010, de 20 de mayo ${ }^{30}$, en cuya exposición de motivos se indicaba que la aplicación de tal reducción se haría «con criterios de progresividad ${ }^{31}$ ». A los pocos días se daba el último paso en el cambio normativo con la publicación de una nueva Instrucción de Nóminas ${ }^{32}$, cuya exposición de motivos -como no podría ser de otra

29 Vid. IN'2010.

30 Real Decreto-ley 8/2010, de 20 de mayo, por el que se adoptan medidas extraordinarias para la reducción del déficit público.

Publicado en el edicto 8228, del BOE núm.126 de 24 de mayo de 2010.

Primera corrección de errores en el edicto 8318, del BOE núm. 127, de 25 de mayo de 2010

Segunda corrección de errores en el edicto 8385, del BOE núm. 128, de 26 de mayo de 2010

31 RDL 8/2010.EM.II.5p.:

[...] No obstante, y con la finalidad de minimizar sus efectos sobre los salarios más bajos las medidas de reducción se aplican con criterios de progresividad para el personal funcionario, $[\ldots]$

32 Vid. IN'2010-r. 
manera dada su jerarquía normativa ${ }^{33}$ - reiteraba tales «criterios de progresividad $^{34}{ }^{3}$.

Cuantitativamente el impacto de lo que dicha reducción salarial, entonces y hasta ahora, supuso y sigue suponiendo resultan evidentes de la mera lectura de las cifras publicadas en el BOE, siendo no pocas las tablas que han circulado por internet, buena parte de ellas emanadas como información sindical, que han puesto de manifiesto sus consecuencias en cifras absolutas y porcentuales.

Cualitativamente lo que el RDL 8/2010 supuso, ha supuesto y sigue suponiendo en los «Sistemas Retributivos» de los Funcionarios Públicos de la LMRFP y posteriormente del EBEP, es muy difícil no calificarlo como una auténtica «revolución»-cuando no "involución», como vocablo más apropiado-. Al respecto, consideramos procedente destacar lo siguiente:

1) Por primera vez se produce una reducción retributiva a los Funcionarios Públicos ${ }^{35}$.

2) Según el legislador ejecutivo, la causa ${ }^{36}$ de esa reducción retributiva, era la necesidad de «reducir, con criterios de progresivi-

33 La manifestación más expresa y evidente de la incuestionable subordinación jerárquica de la IN'2010 respecto al RDL 8/2010 se pone de manifiesto en el 5p de su exposición de motivos donde dice:

[...] con la finalidad de facilitar la confección de las nóminas que han de elaborarse para abonar las mencionadas retribuciones, esta Secretaría de Estado considera oportuno dictar las siguientes instrucciones que se limitan a aplicar estrictamente lo dispuesto en la Ley de Presupuestos Generales del Estado en la redacción dada por el Real Decreto-ley 8/2010, de 20 de mayo y en las precedentes por lo que respecta a sus normas de vigencia indefinida, así como en las restantes normas reguladoras del régimen retributivo del referido personal del sector público estatal con efectos de 1 de junio de 2010. [...]

34 IN'2010-r.5p.:

[...] Las medidas de reducción de retribuciones, con la finalidad de minimizar sus efectos sobre los salarios más bajos, se aplican con criterios de progresividad para el personal funcionario, [...]

35 La ancestral salvaguarda en -cuando menos nominalmente- evitar siempre la existencia disminuciones retributivas funcionariales, tiene sus ejemplos más paradigmáticos en los supuestos de cambio del Sistema Retributivo o de integraciones inherente a transferencias competenciales, en donde, precisamente para neutralizar la posible generación de reducciones retributivas, tradicionalmente ha existido la figura del «Complemento Personal y Transitorio» y más recientemente con el EBEP. DT.primera la de la «Garantía de Derechos Retributivos».

36 RDL 8/2010.EM.I:

El presente Real Decreto Ley contempla las medidas extraordinarias adoptadas para dar cumplimiento al compromiso del Gobierno de acelerar, en 2010 y 2011, la reducción del déficit inicialmente prevista.

La dureza y profundidad de la crisis económica ha llevado a todos los países industrializados a realizar un esfuerzo fiscal significativo para paliar las consecuencias de la crisis y preservar los niveles alcanzados de desarrollo y bienestar. No obstante, 
como consecuencia de esta imprescindible política fiscal expansiva, las finanzas públicas han sufrido un grave deterioro que ahora debe ser corregido como requisito esencial para alcanzar una recuperación económica sólida y duradera.

El compromiso del Gobierno de España con la sostenibilidad de sus finanzas públicas quedó plasmado en la actualización del Plan de Estabilidad y Crecimiento 2010-2013, aprobada por el Consejo de Ministros de 29 de enero de 2010. En la misma se establece como objetivo, de acuerdo con el Procedimiento de Déficit Excesivo abierto por la Unión Europea, la reducción del déficit para el conjunto de las Administraciones Públicas hasta el 3 por ciento del Producto Interior Bruto. Asimismo, también se aprobaron el Plan de Acción Inmediata 2010 y el Plan de Austeridad de la Administración General del Estado 2011-2013 como instrumentos para alcanzar dicho objetivo. Posteriormente, el Consejo de Política Fiscal y Financiera aprobó el Acuerdo Marco con las comunidades autónomas y ciudades con estatuto de autonomía sobre sostenibilidad de las finanzas públicas 2010-2013. Y, en el seno de la Comisión Nacional de Administración Local se aprobó el Acuerdo Marco sobre sostenibilidad de las finanzas públicas para el periodo 2010-2013 en el que se prevé una senda de déficit, en términos de Contabilidad Nacional, para el conjunto de las Entidades locales que va desde el 0,5\% PIB en 2009 al 0,2\% PIB en 2013. Con lo que todas las administraciones públicas se suman al esfuerzo que de forma coordinada debe llevarse a cabo para reducir el déficit público y asegurar la sostenibilidad fiscal a medio plazo.

El Plan de Acción Inmediata 2010 supuso un acuerdo de no disponibilidad de 5 mil millones de euros que afectó a todos los Ministerios y una reducción de la oferta pública de empleo, estableciendo una tasa de reposición del 10\% de las vacantes. Igualmente se aprobó un marzo un plan de racionalización del gasto farmacéutico por importe de 1500 millones de euros y en abril un plan sobre racionalización de estructuras de la Administración General del Estado y un plan de racionalización del sector público empresarial del estado.

Sin embargo, la evolución de la coyuntura económica, así como los compromisos adoptados por nuestro país en el ámbito de la Unión Europea en defensa de la Unión Monetaria y de las economías de la eurozona, hacen necesario anticipar algunas de las medidas previstas en dichos escenarios con la finalidad de acelerar la senda de consolidación fiscal, restableciendo de esta manera la confianza de los mercados en el cumplimiento de las perspectivas de reducción del déficit.

De acuerdo con esta necesidad, el presente Real Decreto-ley recoge una serie de medidas de ajuste que tratan de distribuir de la forma más equitativa posible el esfuerzo que toda la sociedad debe realizar para contribuir a la sostenibilidad de las finanzas públicas.

[...] En el primer capítulo, se recogen las disposiciones encaminadas a reducir, con criterios de progresividad, la masa salarial del sector público en un 5 por ciento en términos anuales. Por su parte, el capítulo II suspende la revalorización de las pensiones públicas para el año 2011, excluyendo las no contributivas y las pensiones mínimas. El capítulo III suprime, para los nuevos solicitantes, la retroactividad del pago de prestaciones por dependencia al día de presentación de la solicitud, estableciéndose, paralelamente, un plazo máximo de resolución de seis meses, cuyo incumplimiento llevará aparejada retroactividad desde la fecha en que se incurra en el mismo. Asimismo, el capítulo IV deja sin efecto la prestación por nacimiento o adopción de 2.500 euros a partir del 1 de enero de 2011. El capitulo V establece una revisión del precio de los medicamentos excluidos del sistema de precios de referencia y la adecuación del número de unidades de los envases de los medicamentos a la duración estandarizada de los tratamientos, así como dispensación de medicamentos en unidosis. Todo ello con el objetivo de reducir los gastos en farmacia. Además, en el capítulo VI se adoptan medidas con el 
dad, la masa salarial del sector público en un 5 por ciento en términos anuales», por la existencia de una "situación de extraordinaria y urgente necesidad», que obligaba a adoptar unas «medidas extraordinarias» para la "reducción del déficit para el conjunto de las Administraciones Públicas hasta el 3 por ciento del Producto Interior Bruto»; todo ello con el objetivo final de «paliar las consecuencias de la crisis y preservar los niveles alcanzados de desarrollo y bienestar». Siendo esta la causa expresada, a la vista de regulación emanada y de los resultados producidos como consecuencia de las medidas adoptadas, no son pocos los cuestionamientos exclusivamente jurídicos que procede plantear:

A) En cuanto al ámbito temporal:

Si se trataba de una medidas «extraordinarias» con un objetivo manifiesto de reducir el déficit al 3\% del PIB, ¿por qué no se incluyó alguna norma que delimitase su vigencia temporal?, o ¿por qué, como mínima concesión a la seguridad jurídica y a la esperanza, no se reguló expresamente algún parámetro que, como condición resolutoria, determinase el fin de las medidas «extraordinarias» y la consecuente vuelta a la normalidad «ordinaria» anterior?...

El tiempo sobradamente ha confirmado la procedencia -cuando no la total necesidad- de una norma de tal naturaleza desde el momento que respecto a las «Pagas Extraordinarias» la reducción retributiva siguió aumentando en el 2011 y en el 2012, y la previsión del 2013 en modo alguno contempla su final, y mucho menos su posible compensación.

B) En cuanto al ámbito subjetivo:

Si se trataba de una situación de extrema y urgente necesidad de todo el Estado, ¿por qué sólo se aplicó la reducción retributiva a determinados colectivos?... Colectivos que además ni eran los causantes de la crisis ni eran los más fuertes para resistirla.

fin de garantizar la contribución de las entidades locales al esfuerzo de consolidación fiscal y de mejora del control de la gestión económica financiera de las citadas entidades. Por último, en el capítulo VII se establecen medidas adicionales tendentes a realizar un control más eficaz del gasto público.

La extraordinaria y urgente necesidad de las reformas aquí contempladas obliga a hacer uso de la habilitación otorgada al Gobierno por el artículo 86 de la Constitución española. De manera que, aún cuando los ciudadanos no vayan a ver afectados sus derechos concretos de forma inmediata por la adopción de alguna estas medidas, es evidente que la aprobación de todas ellas va a producir unos importantes efectos económicos desde esta fecha, directamente orientados a remediar la situación de extraordinaria y urgente necesidad a la que el presente Real Decreto-Ley responde, pues la rapidez, seguridad y determinación en la actuación forma parte del compromiso asumido por los países integrantes de la zona euro para reforzar la confianza en la moneda única y en la estabilidad de la eurozona. [...] 
C) En cuanto a la idoneidad económica de la medida:

Nadie niega que la existencia de un déficit público excesivo es algo, en principio, negativo para la economía. Pero tampoco nadie puede negar que no son pocos quienes ya en el 2010 advirtieron que medidas encaminadas exclusivamente a la austeridad, y que además eran tan inauditas y tan radicales -como era precisamente la reducción de las retribuciones en general y de las «Pagas Extraordinarias» en particular de los Funcionarios Públicos-, además de resultar improcedentes para aquel fin, devendrían totalmente contraindicadas para aquella patología, habida cuenta la reducción del consumo que provocarían y la inseguridad -por no decir miedo atroz- que con ellas se generaría.

3) En cuanto al modo de llevar a término dicha medida, en la $\mathrm{EM}^{37}$ del RDL 8/2010 expresamente se decía que la reducción de un $5 \%$ de la masa salarial del sector público se aplicaría con «criterios de progresividad» "con la finalidad de minimizar sus efectos sobre los salarios más bajos». La profunda trascendencia jurídica de los problemas creados con la articulación técnica realizada de tal criterio a la luz del referido elemento teleológico, obligan a un análisis en profundidad:

A) En cuanto a la articulación técnica llevada a cabo.

A falta de precedentes legislativos, parecía lógico pensar que la dinámica de la reducción salarial debía ser la misma (multiplicada por -1) que la seguida para los aumentos salariales ordinarios (evidentemente cuando no existía congelación salarial de los funcionarios); dicho de otra manera: se aplicaría un mismo porcentaje fijo de reducción a todos los niveles de los diferentes "Conceptos Retributivos». Esta articulación técnica, en primer lugar, respondería al «Principio Retributivo» ${ }^{38}$-que es uno de los fundamentos esenciales del «Sistema Retributivo Funcionarial» de la LMRFP y del EBEP-; en segundo

37 Vid. RDL 8/2010.EM.II.5p.ab initio.

38 El «Principio Retributivo» es aquel que dentro de un «Sistema Retributivo» da respuesta a la pregunta: «¿qué se retribuye?».

En este sentido hasta el RDL 8/2010 en el "Sueldo», en los «Trienios» y en la «Pagas Extraordinarias» como «Conceptos Retributivos,» el «Principio Retributivo» tenía dos manifestaciones:

La manifestación o vertiente cuantitativa, en virtud de la cual se retribuía proporcionalmente al tiempo de prestación de servicio. Por eso una disminución del «Período Retributivo» conllevaba una disminución proporcional de la cuantía devengada.

La manifestación o vertiente cualitativa, en virtud de la cual se retribuía la mayor cualificación o responsabilidad del funcionario. Por eso la pertenencia a un «Grupo /Subgrupo de Clasificación» superior (en tanto en cuanto el acceso al mismo venia condicionaba en función de la titulación exigida) se correspondía con una mayor retribución. 
lugar, respondería a lo que supone el calificativo "progresividad» ${ }^{39}$; y, en tercer lugar, su resultado final supondría que la reducción resultante a los «Grupos / Subgrupos de Clasificación» o con «Nivel de Complemento de Destino» o cuantía de "Complemento Específico» inferiores, sería inferior en términos absolutos a la aplicada a los superiores. Esta articulación técnica fue la que el propio legislador del RDL 8/2010 aplicó respecto al "Complemento de Destino» y al «Complemento Específico», como «Conceptos Retributivos» y como «componentes» de la «Paga Extraordinaria» y de la «Paga Adicional». El problema surge con la regulación que el mismo RDL 8/2010 hace respecto al «Sueldo» y los "Trienios», la cual provoca el siguiente resultado:

a) La reducción del «Sueldo» y los «Trienios» como «Conceptos Retributivos» se concreta en una reducción porcentual diferencial para los «Grupos / Subgrupos de Clasificación».

b) La reducción del «Sueldo» $\mathrm{y}$ «Trienios» como «componentes» de las «Pagas Extraordinarias» se concreta en una reducción porcentual, muchísimo mayor, también diferencial para los «Grupos / Subgrupos de Clasificación».

c) En la Paga Extraordinaria de Diciembre/2010 se produce una desconexión cuantitativa del «Sueldo» $\mathrm{y}$ «Trienios» como «Conceptos Retributivos» y como «componentes» de las «Pagas Extraordinarias».

A la vista de los resultados, causados por el RDL 8/2010 y mantenidos posteriormente hasta la misma previsión de la LPGE'2013, es muy difícil no concluir que la deficiente articulación técnica del referido criterio de "progresividad», precisamente lo que ha provocado es una quiebra de la "progresividad» del «Principio Retributivo». Lo cual se pone de manifiesto de forma paradigmática si observamos lo siguiente:

a) Que respecto al «Sueldo» como componente de la «Paga Extraordinaria», los Funcionarios del «Grupo / Subgrupo de

39 A falta de una interpretación auténtica por parte del legislador del RDL 8/2010 de que es lo que quería decir cuando utilizó el término «progresividad» como criterio; y a falta de una interpretación jurídica específica en el Derecho Funcionarial, de acuerdo con el CC.3.1, la hermenéutica de dicho calificativo necesariamente debe buscarse en el sentido vulgar o no jurídico de la propia palabra, siendo por ello del todo procedente residenciarla en la segunda acepción del término "progresivo» recogida en el DRAEL; donde se define como calificativo de aquello "Que progresa o aumenta en cantidad o en perfección".

Siguiendo esta interpretación devendría del todo procedente afirmar que dentro del «Sistema Retributivo» establecido por la LMRFP y por el EBEP, constituía y constituye un «criterio de progresividad», y además plenamente ajustado al «Principio Retributivo», que la cuantía del «Sueldo» y los «Trienios», como «Conceptos Retributivos» o como «componentes» de la «Paga Extraordinaria», fuese cuantitativamente mayor en función de la progresión en el «Grupo o Subgrupo de Clasificación». 
Clasificación» B perciban en términos absolutos más que los del A2; y que los del A2 perciban más que los del A1.

b) Que respecto a los «Trienios» como componentes de la «Paga Extraordinaria» los consolidados en el «Grupo / Subgrupo de Clasificación» B, sean superiores en términos absolutos a los consolidados en el A2 o en el A1.

B) En cuanto al elemento finalista.

Prima facie podría argumentarse que la razón por la que, como hemos visto, la regulación establecida en el RDL 8/2010 quiebra el «Principio Retributivo» fuese «la finalidad de minimizar sus efectos sobre los salarios más bajos». Avanzando en esta línea argumental incluso habría quien viese en la articulación técnica de esos «criterios de progresividad", a la luz del referido elemento teleológico, un paralelismo en el gasto público con la progresividad exigida respecto a los ingresos públicos tributarios en el artículo 31.1 de nuestra Constitución, el cual proclama el «Principio de Capacidad Económica mediante un sistema tributario justo inspirado en los principios de igualdad y progresividad». Incluso en el corolario argumental también habría quien atisbase que el Principio de Progresividad respecto a los ingresos tributarios, concretado en el IRPF en el hecho que el Sujeto Pasivo con mayor renta ha de soportar un Tipo Impositivo superior, a través del «criterio de progresividad» del RDL 8/2010 hubiese extendido su filosofía al ámbito de la reducción de gastos públicos, concretándose en la articulación técnica de la reducción de las retribuciones relativas al «Sueldo» y a los «Trienios» como «Conceptos Retributivos» y como componentes de la «Paga Extraordinaria», de tal manera que a los Funcionarios con un «Grupo / Subgrupo de Clasificación» superior se les aplicase un porcentaje de reducción también superior.

Nuestro contraargumento partiría de recordar que en el mismo artículo 31.1 de la CE se proclama el Principio de Progresividad y el Principio de Capacidad Económica en la contribución al sostenimiento de los gastos públicos, y que tal coexistencia en la sede normativa no es casual, dada la íntima relación ontológica existente entre ambos principios. Es más, precisamente porque esto es así, en el IRPF la conjunción del Principio de Capacidad Económica del Contribuyente y del Principio de Progresividad se manifiestan en que el Tipo Impositivo sea superior para quien tenga mayor renta; que no para quien tenga mayor salario (y ello a pesar de que el salario sea una fuente de renta en el IRPF). Esta matización, en absoluto baladí, llevada al campo del Derecho Funcionarial en el contexto argumental que estamos exponiendo permitiría afirmar que el hecho que un Funcionario pertenezca a un «Grupo / Subgrupo de Clasificación» superior necesariamente no significa que tenga que tener una mayor capacidad económica; y viceversa, la pertenencia a uno menor per se necesariamente tampoco significa que su capacidad económica tenga que ser menor. Es más, si nadie duda que responda a Principios de Justicia 
Material que cualquier medida que se adopte, sea de ingresos o de gastos públicos, debe ser más protectora o más benevolente con los más débiles, tampoco nadie debería dudar la procedencia de matizar que la circunstancia de fortaleza o debilidad no necesariamente tiene porqué corresponder con la pertenencia de un funcionario a un determinado «Grupo / Subgrupo de Clasificación»; lo cual no niega que la diferencia retributiva no sea un factor de ponderación importante -pero no el único- en la determinación de la Capacidad Económica.

Siendo esto así, jurídicamente seria rechazable desde su misma base que desde el punto de vista de gastos públicos, ante una situación de extraordinaria necesidad, amparándose formalmente en un pretendido "criterio de progresividad» (posiblemente inspirado en el constitucional Principio de Progresividad de los ingresos públicos tributarios), técnicamente se articulase una aplicación que hiciese absoluta preterición del «Principio de Capacidad Económica» (residenciado como Principio Tributario en el mismo artículo constitucional que el «Principio de Progresividad»); lo cual incluso podría dar lugar -y desgraciadamente casos no faltarían que lo confirmasen- a resultados extremadamente injustos, en tanto buscando minimizar los efectos de la reducción sobre los salarios más bajos, perfectamente se podría acabar dañando a quienes tuviesen menor capacidad económica.

Consecuentemente a lo expuesto resulta inevitable concluir que la articulación técnica que el RDL 8/2010 hizo de la reducción de un $5 \%$ de la masa salarial del sector público aplicando «criterios de progresividad» "con la finalidad de minimizar sus efectos sobre los salarios más bajos», por una parte, quiebra la «progresividad» del «Principio Retributivo», lo cual distorsiona gravemente la dinámica del «Sistema Retributivo Funcionarial» (tanto de la LMRFP como del EBEP) y, por otra parte, ignora totalmente el Principio de Capacidad Económica pudiendo degenerar en situaciones de máxima injusticia.

\section{AÑO 2011}

El artículo 22.Dos de la LPGE'2011 formalmente proclamó una nueva «congelación» salarial de los Funcionarios Públicos durante el ejercicio 2011, sin embargo la lectura de la regulación establecida en el artículo 22.Seis. 2 de la misma ley indubitativamente evidenciaba la existencia material de una segunda reducción salarial desde el momento que la cuantía de los componentes de «Sueldo» y «Trienios» de las «Pagas Extraordinarias» de junio'2011 y diciembre'2011 no serían las de junio'2010 y diciembre'2010, sino que serían las reducidas con «criterios de progresividad» de esta última; eso sí, con unas mínimas diferencias porcentuales de incremento que en todo caso no compensaban el resultado final de significativa reducción. 
El 28 de julio de 2011, el Presidente del Gobierno José Luis Rodríguez Zapatero anunció elecciones anticipadas ${ }^{40}$. El 20 de noviembre de 2011 el PP ganó las elecciones obteniendo 186 diputados, lo cual hizo que la $\mathrm{X}$ legislatura se iniciase siendo investido Presidente del Gobierno Mariano Rajoy Brey.

A pesar de adoptar una medida tan importante a nivel de Función Pública como fue el establecimiento de la jornada mínima de 37,5 h a través del Real Decreto-ley 20/2011, de 30 de diciembre, de medidas urgentes en materia presupuestaria, tributaria y financiera para la corrección del déficit público, en el año 2011 no se adoptaron medidas en relación a las retribuciones strictu sensu ${ }^{41}$.

\section{AÑO 2012}

El año 2012 comenzó con un presupuesto prorrogado hasta la publicación el 30 de junio de 2012 de la LPGE'2012. El artículo 22. Dos de dicha ley volvía a establecer una nueva congelación salarial de los «Funcionarios Públicos». Por su parte el artículo 22.Cinco.2 regulaba el componente de «Sueldos» $\mathrm{y}$ «Trienios» de las «Pagas Extraordinarias» repitiendo las cifras del 2011.

El 11 de julio de 2012 anno domini cristiano -11 de Tamuz del año 5772 de la creación del mundo según el calendario judío; 21 de Sha'ban de 1433 de la Hégira, según el calendario musulmán-, el Presidente del Gobierno Mariano Rajoy Brey, 11 días después de publicarse la LPGE'2012 en la cual se regulaba la cuantía de las «Pagas Extraordinarias» de junio/2012 y diciembre/2012, también

${ }^{40}$ No constituye objeto de este artículo el análisis de las causas del adelanto electoral. Pero a la luz de las hemerotecas, videotecas y correos y comentarios anónimos evacuados en el mundo virtual resultaría plausible pensar que la causa fuese la crisis y determinados aspectos de la misma: La actitud del Gobierno y de su Presidente en negarla, las medidas antisociales que adoptó -muchas de las cuales se dirigieron contra la línea de flotación de la Función Pública- y el fracaso de las medidas adoptadas. Pero no negamos que también fuese plausible pensar en otras causas.

La cronología de este anticipo electoral presenta circunstancias que llaman la atención: En primer lugar su dilación temporal teniendo en cuenta la necesidad de un gobierno fuerte y estable ante la magnitud de la crisis (el anuncio se produjo el 28 de julio, la convocatoria electoral fue el 26 de septiembre y las elecciones fueron el 20 de noviembre); en segundo lugar el hecho que realmente el anticipo electoral fue menor de 4 meses (cuando desde el anuncio a las elecciones casi transcurrieron 4 meses) y, en tercer lugar, la elección de la fecha (aniversario de la muerte Franco).

41 Es verdad que formalmente no se adoptaron medidas retributivas, pero materialmente la medida incidió en las retribuciones de los Funcionarios Públicos toda vez que con el referido RDL 20/2011 la retribución por hora de prestación de servicios evidentemente disminuyó. 
pasa a la historia de la Función Pública anunciando que [...] dadas las circunstancias de la economía, excepcionalmente graves, pedimos un esfuerzo, también excepcional, a los empleados y altos cargos públicos. En este año 2012, se suspenderá el abono de la segunda paga extraordinaria. [...]. A los pocos días ese anuncio se materializa en el Real Decreto-ley 20/2012, de 13 de julio, de medidas para garantizar la estabilidad presupuestaria y de fomento de la competitividad ${ }^{42}$.

En un lapso de tiempo de 2 años y 2 meses, 2 Presidentes del Gobierno adoptaron 2 medidas... ¿similares o análogas?. Y decimos esto porque la primera cuestión que cabe formularse es si la diferencia entre ambas medidas (referidas a las retribuciones en general y a las «Pagas Extraordinarias» en particular) era cualitativa o exclusivamente cuantitativa.

La segunda cuestión jurídico técnica que inmediatamente se pone de manifiesto es que indudablemente la «Paga Extraordinaria» de diciembre/2012 no se cobró, pero ¿está «suspendida» o «suprimida»... o «aplazada»?. Las dos evidencias más contundentes de esta duda se encuentran, por una parte, en el mismo discurso del 11 de julio de 2012 del Presidente del Gobierno Mariano Rajoy Brey, en donde se utilizan los términos «suspensión» y "supresión» como si fuesen análogos ${ }^{43}$; y en lo manifestado día 12 de noviembre de 2013, en el Pleno del Congreso de Diputados, en el debate de la Ley de Pre-

\footnotetext{
42 Publicado en el edicto 9364, del BOE núm. 168 de 14 de julio de 2012.

43 Discurso del Presidente del Gobierno Mariano Rajoy Brey de 11 de julio de

[...] En este año 2012, se suspenderá el abono de la segunda paga extraordinaria.
} 2012: $[\ldots]$.

En RDL 20/2012.EM.II.13p.ab initio dice que [...] Se suprime durante el año 2012 la paga extraordinaria del mes de diciembre y la paga adicional de complemento específico o pagas adicionales equivalentes del mes de diciembre. [...]; pero acto seguido, en el segundo inciso también dice [...] Las cantidades derivadas de esa supresión podrán destinarse en ejercicios futuros a realizar aportaciones a planes de pensiones o contratos de seguro colectivo [...].

En el articulado del RDL 20/2012 el artículo 2.1 habla de [...] la supresión tanto de la paga extraordinaria como de la paga adicional de complemento específico o pagas adicionales equivalentes de dicho mes. [...].

Pero sin ningún tipo de dudas la joya de la corona se encuentra en el artículo 2.4 del RDL 20/2012 donde tras volver ratificar la supresión iniciando la frase con la redacción: [...] Las cantidades derivadas de la supresión de la paga extraordinaria y de las pagas adicionales de complemento específico o pagas adicionales equivalentes [...], culmina la frase afirmando que [...] de acuerdo con lo dispuesto en este artículo se destinarán en ejercicios futuros a realizar aportaciones a planes de pensiones o contratos de seguro colectivo que incluyan la cobertura de la contingencia de jubilación, con sujeción a lo establecido en la Ley Orgánica 2/2012, de Estabilidad Presupuestaria y Sostenibilidad Financiera y en los términos y con el alcance que se determine en las correspondientes leyes de presupuestos. [...]. 
supuestos Generales del Estado de 2014, por el Ministro de Hacienda y Administraciones Públicas Cristóbal Ricardo Montoro Romero, cuando precisamente matizo que la «Paga Extraordinaria» de Navidad de 2012 no fue "suprimida», sino "aplazada» ${ }^{44}$.

La aplicación de la suspensión/supresión/aplazamiento desgraciadamente no supuso una excepción a una constante de defectuosa articulación técnica, constituyendo la cotización de lo no cobrado y la no percepción de lo devengado sus dos manifestaciones más paradigmáticas.

Por otra parte, habida cuenta que las cuantías de los «Grupos / Subgrupos de Clasificación» de los componentes de «Sueldo» y «Trienios» de la «Paga Extraordinaria» de Junio/2012 seguían siendo las mismas del año anterior, mutatis mutandi procede tener por repetido lo que ya se ha dicho respecto a dicha medida a raíz del RDL 8/2010.

\section{AÑO 2013}

La LPGE'2013 sigue manteniendo la congelación salarial, incluyendo en ella los componentes de «Sueldo» y «Trienios» de las «Pagas Extraordinarias», por lo que, también mutatis mutandi, por 4. ${ }^{\circ}$ año procede tener por reiterado lo dicho respecto al RDL 8/2010.

Desgraciadamente la única novedad es que es si bien es verdad que el artículo 26.Uno.B) de la LPGE’2013 contempla las dos «Pagas Extraordinarias»; no es menos verdad que a lo largo del año ha existido el gran temor de si al final realmente llegarán a pagarse ${ }^{45}$; y la mera existencia de esta duda, per se, nada de bueno tiene para la recuperación económica.

${ }^{44}$ Sobre este particular procede destacar el siguiente artículo aparecido en la revista electrónica EXPANSION.COM:

Agencias, "Montoro: La extra no fue suprimida, sino aplazada», EXPANSION. COM, 12 de noviembre de 2013, en http://www.expansion.com/2013/11/12/funcionpublica/1384271925.html:

[...] Respecto a la extra de Navidad de 2012, el titular de Hacienda ha asegurado que el Gobierno no ha suprimido la paga a los empleados públicos, sino que únicamente ha aplazado su cobro en el tiempo, aunque ha asegurado que acata la sentencia de un juzgado de Palencia a favor de tres funcionarios. [...]

45 Prueba de la existencia de la duda -argumentada con el Principio Excusatio non petita acusatio manifiesta- fueron las manifestaciones, no casuales, hechas el viernes 12 de abril de 2013 por el Ministro de Hacienda y Administraciones Públicas Cristóbal Montoro y por su Secretario de Estado de Administraciones Públicas Antonio Beteta, reiterando su pago. 


\section{ABREVIATURAS}

AAS'2003-4 RESOLUCIÓN de 15 de noviembre de 2002, de la Secretaría de Estado para la Administración Pública, por la que se ordena la publicación del acuerdo de Consejo de Ministros de 15 de noviembre de 2002, por el que se aprueba el acuerdo Administración-Sindicatos para el período 2003-2004, para la modernización y mejora de la Administración Pública.

AAS'2006 Acuerdo Administración-Sindicatos sobre medidas retributivas y de oferta de empleo público para el año 2006.

BOE Boletín Oficial del Estado

$\mathrm{CC}$ Código Civil.

$\mathrm{CE}$ Complemento Específico.

CE'78 Constitución Española

CD Complemento de Destino.

DRAEL Diccionario de la Real Academia Española de la Lengua

DT

EBEP

Disposición Transitoria

Ley 7/1987, de 12 de abril, por el que se aprueba el Estatuto Básico del Empleado Público.

EM

IN'2010

Exposición de Motivos.

Resolución de 4 de enero de 2010, de la Secretaría de Estado de Hacienda y Presupuestos, por la que se dictan instrucciones en relación con las nóminas de los funcionarios incluídos en el ámbito de aplicación de la Ley 30/1984, de 2 de agosto, en los términos de la Disposición Final Cuarta de la Ley 7/2007, de 12 de abril, del Estatuto Básico del Empleado Público, y se actualizan para el año 2010 las cuantías de las retribuciones del personal a que se refieren los correspondientes artículos de la Ley de Presupuestos Generales del Estado para dicho ejercicio.

IN'2010-r Resolución de 25 de mayo de 2010, de la Secretaría de Estado de Hacienda y Presupuestos, por la que se dictan instrucciones en relación con las nóminas de 
los funcionarios incluidos en el ámbito de aplicación de la Ley 30/1984, de 2 de agosto, en los términos de la Disposición Final Cuarta de la Ley 7/2007, de 12 de abril, del Estatuto Básico del Empleado Público, y se actualizan con efectos de 1 de junio de 2010 las cuantías de las retribuciones del personal a que se refieren los correspondientes artículos de la Ley de Presupuestos Generales del Estado para dicho ejercicio.

LALPGE'2003 LEY 53/2002, de 30 de diciembre, de Medidas Fiscales, Administrativas y de Orden Social.

LMRFP

Ley 30/1984, de 2 de agosto, de medidas para la Reforma de la Función Pública.

LPGE'2003 Ley 52/2002, de 23 de diciembre, de Presupuestos Generales del Estado para el año 2003

LPGE'2004 Ley 61/2003, de 30 de diciembre, de Presupuestos Generales del Estado para el año 2004

LPGE'2005 Ley 2/2004, de 27 de diciembre, de Presupuestos Generales del Estado para el año 2005

LPGE'2006 Ley 30/2005, de 29 de diciembre, de Presupuestos Generales del Estado para el año 2006

LPGE'2007 Ley 42/2006, de 28 de diciembre, de Presupuestos Generales del Estado para el año 2007

LPGE'2008 Ley 51/2007, de 26 de diciembre, de Presupuestos Generales del Estado para el año 2008

LPGE'2009 Ley 2/2008, de 23 de diciembre, de Presupuestos Generales del Estado para el año 2009

LPGE'2010 Ley 26/2009, de 23 de diciembre, de Presupuestos Generales del Estado para el año 2010

LPGE'2011 Ley 39/2010, de 22 de diciembre, de Presupuestos Generales del Estado para el año 2011

LPGE'2012 Ley 2/2012, de 29 de junio, de Presupuestos Generales del Estado para el año 2012

LPGE'2013 Ley 17/2012, de 27 de diciembre, de Presupuestos Generales del Estado para el año 2013

LRBRL Ley 7/1985, de 2 de abril, reguladora de las Bases de Régimen Local. 
RDL 8/2010 Real Decreto-ley 8/2010, de 20 de mayo, por el que se adoptan medidas extraordinarias para la reducción del déficit público.

RDL 20/2012 Real Decreto-ley 20/2012, de 13 de julio, de medidas para garantizar la estabilidad presupuestaria y de fomento de la competitividad.

Las referencias de las sentencias citadas entre paréntesis corresponden a la base de datos de WESTLAW-ARANZADI. 